thesia proposed by van Ilmer has had little support and has been generally disearded by those who have used it.

Sacral anesthesia, as first used by Cathélin, has given rather satisfactory results and has been recommended by various obstetricians, especially Stoeckel. Various operators have used solutions containing $1 / 2$ to 2 per cent novocaine usually with sodium chloride or bicarbonate as well as adrenalin. From 20 to 30 c.c. are injected into the sacral canal while the patient lies with her hips slightly raised and the knees drawn up. After the needle is inserted, and before injecting the solution, the piston is withdrawn partly to exclude the possibility oi injecting into a vein. Since all methods of analgesia have a tendency to weaken the pains, Schellekens made his injections only after the cervix was dilated and then noticed no effect on the contractions. If necessary, a further injection of 10 e.c. may be made. His results have been very satisfactory and he reports absolute analgesia in his cases, some patients experiencing merely a feeling of prossure as the head passes over the perineum.

R. E. WoвUs.

Gillespie: Relief of Pain in Labor. Ohio State Medical Journal, 1921, xvii, 669.

The author is an advocate of chloroform as an analgesic for the country doetor who must meet all kinds of emergencies and cannot carry a complicated apparatus everywhere he goes. He gives ehloroform only at the beginning of the pain before the patient is aware that the pain is coming. The patient takes three or four breaths and then is made to bear down the same as in the use of nitrous oxide. The article includes a discussion on how to administer chlorotorm in a normal delivery; handling difficulties in obstetrical anesthesia; objections to anesthesia in labor; anesthesia in the first stage; the prevention of septic infection and conditions foretelling diffeult and tedious labor. This is an excellent article especially for recent graduates, who are familiar only with the adverse side of chloroform.

W. K. Fostel.

\title{
Danforth: Nitrous Oxide-Oxygen Analgesia and Anesthesia in Normal and Opera-
}

tive Obstetrics. The Pennsylvania Medical Journal, 1921, xxiv, 383.

The paper is based on about seventeon hundred obstetrical cases in which nitrous oxide-oxygen analgesia or anesthesia was used.

'The author's technic consists in beginning the administration of the gas at the onset of the second stage. The mask is placed over the face and the patient instructed to breathe deeply and quickly, the number of breaths required varying between three and eight, depending on the individual. It is essential for the best results to begin the administration of the gas immediately at the onset of a pain. The use of oxygen with the nitrous oxide is advised in percentages from five to fiteen according to the individual requirements. Cyanosis should be avoided at all times. With the end of the second stage a littie ether is added to advantage.

The course of labor is not slowed by a properly given gas analgesia, on the contrary the effectiveness of each contraction is increased because of the marked relief from pain and the voluntary cooperation of the patient. The danger of postpartum hemorrhage is not increased. The nitrous oxide does not relax the uterine musculature to the same degree as other anestheties. No untoward effect of the gas was noticed in the infants and in no instance could the nitrous oxide analgesia be charged with causing fetal death.

For various operative procedures as repair of the perineum, low forceps, induction of labor by the introduction of a hydrostatic bag; and in eclamptic or 